\title{
Conditioned suppression and discriminative control of behavior*
}

\author{
D. E. BLACKMAN and PAMELA SCRUTON \\ University of Birmingham, Birmingham, England
}

\begin{abstract}
Rats were trained on a multiple variable-interval extinction schedule of reinforcement. The effects of a stimulus which preceded an unavoidable shock were assessed when it was superimposed on both components of the schedule or on $V I$ components only. In general, VI responding was suppressed during the preshock stimulus. There was no evidence for any increase in responding during extinction components either generally or differentially during the preshock stimulus. These findings fail to support an earlier suggestion that a preshock stimulus may impair discrimination performances.
\end{abstract}

Procedures in which an originally neutral stimulus terminates with an unavoidable electric shock have been superimposed on many different patterns of operant behavior. Their effects were first reported by Estes and Skinner (1941); generally, these may be described as the suppression of appetitive responding during the preshock stimulus, a phenomenon now of ten termed conditioned suppression (Lyon, 1968). The effects of the procedure on discrimination performances are as yet unclear. however.

Hearst (1965) trained rats on a schedule which occasionally reinforced leverpresses in the presence of one stimulus (variable-interval schedule of reinforcement: VI), but not in the presence of another (extinction). Conditioned suppression procedures were then superimposed on some of the VI periods. Hearst reported the typical differential suppression of responding during the preshock stimulus; however, there was also some general suppression of VI responding which, together with an enhanced rate of responding during extinction periods, resulted in a deterioration in the efficiency of discrimination performance (expressed in terms of a comparison between VI and extinction response rates).

Weiss (1968) replicated Hearst's procedures, but produced conflicting results. When stimulus-shock pairings were superimposed on some of his periods of VI schedule, Weiss found almost complete response suppression during the preshock stimulus. However, although there was also general suppression of VI responding, the efficiency of the discrimination was unimpaired.

Neither of these experiments was a conventional conditioned suppression study, in the sense that their

\footnotetext{
*This research was supported by Grant $969 / 430 / C$ from the Medical Research Council, L.K., for which the authors are indebted. The experiment was performed in the University of Nottingham. Reprints may be obtained from Dr. D. E. Blackman, Department of Psychology, University of Birmingham, P.O. Box 363, Birmingham B15 2TT, England.
}

major emphases relate to changes in behavior outside the preshock stimulus, i.e., to changes in the behavioral baselines. Most conditioned suppression studies have been concerned with differential effects of a preshock stimulus on responding, and partial disruption (or sometimes complete loss) of the baseline behavior has usually been considered more a serious procedural problem than a major finding (e.g., Hoffman \& Fleshler, 1965).

Although Hearst's (1965) major finding relates to responding during periods of extinction. neither he nor Weiss (1968) superimposed a preshock stimulus on extinction periods. Furthermore, their extinction periods were relatively short and accounted for only one-sixth of each experimental session. The present experiment was designed to assess the effects of conditioned suppression procedures on extinction responding when the preshock stimulus was superimposed on VI periods only (as in the previous experiments) or on both VI and extinction periods. Experimental sessions were equally divided between periods of VI and of extinction. The experiment was designed, therefore. to elucidate the effects of the Estes-Skinner procedure on an operant discrimination.

\section{METHOD}

Subjects

Three experimentally naive male rats of the hooded Lister strain served as Ss. They were approximately 150 days old and were maintained at $85 \%$ of their free-feeding weights. Each was approximately $22 \mathrm{~h}$ food-deprived at the start of each experimental session.

\section{Apparatus}

The test chamber was a standard Grason-Stadler two-lever rat chamber in which only one lever was operative. Pellets of food weighing $45 \mathrm{mg}$ ( $\mathrm{P}$. J. Noyes \& $\mathrm{Co}$.) were used as reinforcers. A 10-W light shielded by a green jewel was located near the roof of the chamber above the food hopper and illuminated the test chamber throughout each experimental session. White noise could be delivered through a speaker located beneath the 

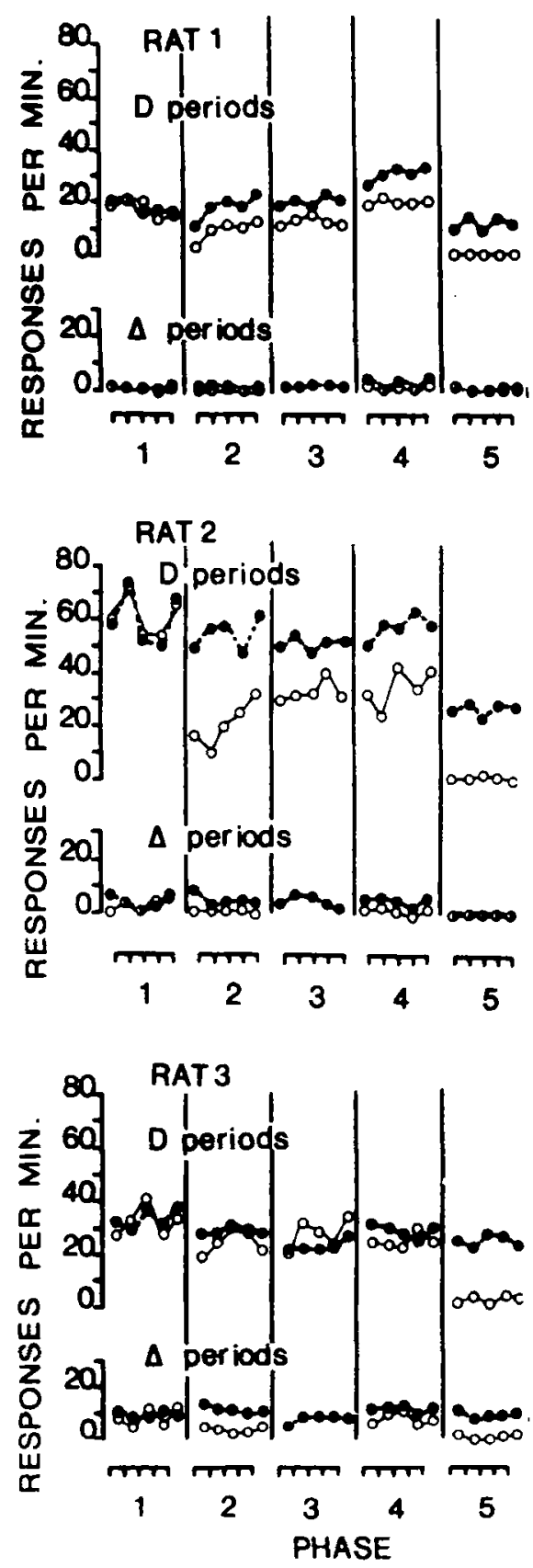

Fig. 1. Summary of results obtained from the last five sessions of each phase of the experiment. Mean response rates are shown in the absence and presence of the flashing-light stimulus by filled and open circles. respectively, both during periods of VI (D) and extinction $(\Delta)$.

operative lever. The preshock stimulus consisted of a red light and a white light, approximately $25 \mathrm{~cm}$ apart, flashing alternately every $1 / 2 \mathrm{sec}$. Electric shock could be delivered through the grid lloor of the chamber from a shock generator and associated scrambler (Grason-Stadler E1064). The experiment was automated by means of electromechanical relay's and timers housed in an adjacent room. Responses and reinforcements were recorded on digital counters and cumulative digital printers. while a cumulative recorder provided a continuous display of the rats' leverptessing behavior for monitoring purposes.

\section{Procedure}

In the presence of continuous white noise $\left(S^{D}\right)$, the rats were magazine trained and received five sessions in which each leverpress was reirforced. Next, each rat was trained on a schedule in which 2 -min periods of white noise alternated with similar periods during which the noise was absent. In the presence of the noise stimulus, each leverpress was reinforced as before, but when the noise was absent, responses had no programmed consequence (extinction).

Following this, each period of the noise $S^{\mathbf{D}}$ and of extinction was lengthened to $7 \mathrm{~min}$. and there were eight $7-\mathrm{min}$ components in each session. Periods of noise and periods without noise were presented in a pseudorandom sequence such that no more than two similar periods occurred consecutively. The noise now accompanied a VI 30-sec schedule of reinforcement. During extinction periods, responses were counted but were never reinforced. This schedule may therefore be specified as a multiple VI 30-sec extinction schedule.

When the multiple schedule had been in operation for 25 consecutive daily sessions, the following procedures were introduced.

Phase I

Periods of VI and extinction were presented as before. The flashing-light stimulus was introduced $3 \mathrm{~min}$ after the beginning of each component for a duration of $1 \mathrm{~min}$. This was continued for six sessions.

\section{Phase?}

Each 1-min period of flashing lights was now terminated with an unavoidable shock $(0.3-\mathrm{mA} \quad 0.5-\mathrm{sec}$ nominal values). This procedure continued for 30 successive sessions.

\section{Phase 3}

In order to make comparisons with Hearst's (1965) procedure. the stimulus-shock pairings were removed from extinction components and were therefore superimposed only on VI components for 15 experimental sessions.

\section{Phase 4}

Stimulus-shock pairings were reinstated on extinction components. Experimental conditions were therefore identical to those in Phase 2. Phase 4 continued for 15 sessions.

Phase 5

The shock intensity was increased to $1.0 \mathrm{~mA}$ (nominal), stimulus-shock pairings still being superimposed on both VI and extinction components. This continued for 25 sessions.

\section{RESULTS}

The data presented were derived from the last five sessions of each experimental phase. Figure 1 shows the mean VI and extinction response rates in the presence and absence of the flashing-light stimulus.

With all rats, the data from Phase 1 of the experiment show that an efficient discrimination had been established between periods of VI and extinction (denoted by $\mathrm{D}$ and $\Delta$, respectively. in Fig. 1). Very low rates of responding occurred in extinction periods and much higher response rates during VI periods. In addition. Fig. 1 shows that periods of hashing lights 
(without shock) superimposed on both VI and extinction periods had no consistent effect on response rates (Phase 1). When each period of flashing lights ended with a $0.3 \cdot \mathrm{mA}$ shock, however (Phase 2), the VI response rates were generally suppressed during the preshock stimulus, although Rat 3 showed this effect to a lesser extent than the others. The very low response rates during extinction periods would make it difficult to produce a similarly consistent suppression of this behavior: however. where any differential effect can be detected. it is in the direction of suppression (see Rat 3 ). Certainly there is no evidence for any increase in extinction response rates during the periods of flashing lights. Nor may evidence be detected for any general increase in extinction responding in the absence of the preshock stimulus. In Phase 3. when the flashing lights and shock occurred only during VI periods, the data obtained do not differ substantially from those obtained in Phase 2. except in the case of Rat 3, which showed a slight increase in VI responding during the preshock stimulus. This finding is somewhat unusual and may be related to a downward drift in overall VI responding between Phases 1 and 3 of the experiment with this rat, at a time when the preshock stimulus was affecting this behavior only marginally. The data depicted for Phase 4 (lights and shock on both VI and extinction periods) are similar to those obtained in the same conditions previously in Phase 2 . When the shock intensity was increased from $0.3 \mathrm{~mA}$ to $1.0 \mathrm{~mA}$ (Phase 5), the VI responding of all rats was more suppressed during the preshock stimulus. Indeed, Rats 1 and 2 showed complete conditioned suppression of VI responding in this phase. and their rates of VI responding in the absence of the preshock stimulus also decreased somewhat. Once more, there was no evidence from any of the animals for any increase in extinction responding, either generally during extinction periods or differentially during the preshock stimulus; in fact, the only differential effect observed was the suppression of Rat 3's extinction responding during the preshock stimulus.

\section{DISCUSSION}

In his earlier paper. Hearst (1965) reported that the efficiency of his rats' discrimination performance was disrupted by superimposing the Estes-Skinner procedure on VI periods only. This deterioration was largely attributed to increases in the frequency of extinction responding, which Hearst related to the Pavlovian concept of "disinhibition."

The principal effect of the Estes-Skinner procedures with all rats in this study was the suppression of both VI and extinction responding during the preshock stimulus. With the higher shock intensity, there was also some general distuption of the behavioral baselines. There was no evidence in any phase of the experiment for an increase in extinction responding attributable to the Estes-Skinner procedure, either in general terms (by comparison with response rates in Phase 1) or differentially during the preshock stimulus. With the higher shock intensity (Phase 5), the results from Rats 1 and 2 have similarities with those reported by Weiss (1968). i.e., almost complete suppression of all responding during the preshock stimulus and some disruption of both VI and extinction baselines.

The results from all three rats in this experiment, then. ofter little support for Hearst's findings (1965) and appear. therefore, to be more in accord with those of Weiss (1968). The latter suggested that the discrepancy between his results and Hearst's may have been due to differences in the discriminative control exerted in their respective experiments, Hearst's animals being under poorer control in this respect. It might be noted in the present experiment that Rat 3 could be described as under poorer discriminative control than the other two rats (viz. the consistent responding during extinction periods with this animal), yet its results show little support for Weiss's suggestion. Indeed. this consistent but low rate of responding served only to emphasize the lack of any increases in extinction responding and to demonstrate the differential conditioned suppression of such responding during the preshock stimulus.

The present experiment failed to produce increases in response rate during extinction periods when a preshock stimulus was superimposed on VI components only; it also failed to increase extinction responding during a preshock stimulus superimposed on extinction periods. These results may therefore be taken to extend Weiss's (1968) failure to replicate Hearst's findings directly. The reasons for these important inconsistencies in the literature remain to be identified by further experiments.

\section{REFERENCES}

Estes. W. K.. \& Skinner, B. F. Some quantitative properties of anxiety. Journal of Experimental Psychology, 1941, 29, $390-400$.

Hearst. E. Stress-induced breakdown of an appetitive discrimination. Journal of the Experimental Analysis of Behavior, 1965, 8, 135-146.

Hoffman. H. S., \& Fleshler, M. Stimulus aspects of aversive controls: The effects of response-contingent shock. Journal of the Experimental Analysis of Behavior, 1965, 8, 89-96.

Lyon. D. O. Conditioned suppression: Operant variables and aversive control. Psychological Record, 1968, 18, 317-338.

Weiss, K. M. Some effects of the conditioned suppression paradigm on operant discrimination performance. Journal of the Experimental Analysis of Behavior, 1968, 11.767-775

(Received for publication August 3, 1972; revision received October 17,1972 .) 